\title{
ASPECTOS DA COMPETÊNCIA JULGADORA DOS TRIBUNAIS DE CONTAS
}

\author{
Augusto Sherman CavalCanti ${ }^{1}$
}

\begin{abstract}
1. Introdução. 2. O dever constitucional de prestar contas. 3. A competência constitucional de julgar contas. 4. As três dimensões do processo de contas. 5. A dimensão política: o julgamento da gestão. 6. A dimensão sancionatória: a punibilidade do gestor faltoso. 7. A dimensão indenizatória: a reparação do dano causado ao erário. 8 . Deve o processo se extinguir com a morte do gestor? 9. Quem é o titular das contas? 10. A quem se deve dirigir a citação ou a audiência prévia? 11. Que é quitação? 12. A quem se deve dar quitação? 13. Como proceder no exame de casos concretos relativos a gestor falecido? 13.1. A hipótese de boa gestão. 13.2. A hipótese de má gestão sem a ocorrência de dano. 13.3. A hipótese de má gestão com a ocorrência de dano. 14. Conclusão.
\end{abstract}

\section{l. Introdução}

Este texto é uma adaptação do artigo "O processo de Contas no TCU: o caso do gestor falecido", de minha autoria, publicado na Revista do $T C U \mathrm{n}^{\circ} 81$, de jul-set de 1999, disponível na página do TCU na internet no endereço www.tcu.gov.br/isc/ sedip/Revista/RevDisponiveis.html.

Ao instruir processos de contas em que o gestor responsável já havia falecido, apresentaram-se diversos problemas que me levaram a refletir sobre a competência julgadora dos Tribunais de Contas e sobre os correspondentes processos em que se exerce essa competência na busca de soluções juridicamente adequadas.

São ricas as questões-problema que se apresentam, por exemplo: o processo deve se extinguir com a morte do gestor? Se não se extingue, quem deve ter as contas

1 Ministro-substituto do Tribunal de Contas da Uniāo.

R. Dir. Adm., Rio de Janeiro, 237: 327-339, Jul./Set. 2004 
julgadas? Ou seja, quem é o titular das contas? É o gestor morto? Ou a titularidade das contas deve ser transferida aos sucessores? A quem se dirige a citação ou a audiência prévia, na hipótese de má gestão dos recursos? Após o julgamento das contas, a quem se deve dar quitação? Que é quitação? É possível dar quitação a pessoa já falecida, tendo em vista que a morte extingue a personalidade?

Não temos a pretensão, neste texto singelo. de esgotar o tema, em razão de sua complexidade. Queremos apenas lançar uma primeira proposta de sistematização e equacionamento do problema e submetê-la ao debate daqueles que se interessarem pelo assunto.

Para tanto procedemos à análise essa competência julgadora, sobretudo o processo de julgamento de contas, na intenção de identificar suas partes e com isso compreendê-los melhor.

Mas antes convém relembrar a origem e as regras que regem a competência de julgar contas dos Tribunais de Contas, bem assim as que regem o dever de prestar contas.

\section{O dever constitucional de prestar contas}

Contas é, a meu ver, o conjunto probatório - em regra, documental - que reflete os atos de gestão de determinados bens e valores públicos ou, em alguns casos, privados, praticados por determinado gestor, em determinado período de tempo.

O dever de prestar contas tem estatura constitucional e é um dos ícones do regime republicano. Com a República, os recursos arrecadados da sociedade deixaram de ser propriedade do rei — situação que perdurou até o antigo regime surgindo então o dever de prestar contas, vez que quem geria não era dono, mas apenas administrador desses recursos.

Nosso texto constitucional prevê que "prestará contas qualquer pessoa física ou jurídica, pública ou privada, que utilize, arrecade, guarde, gerencie, ou administre dinheiros, bens e valores públicos ou pelos quais a União responda, ou que, em nome desta, assuma obrigações de natureza pecuniária" (art. $7^{\circ}$, parágrafo único, com redação dada pela EC 19/98).

Assim, incumbe prestar contas, primeiro, quaisquer espécie de pessoas, físicas, jurídicas, públicas, privadas, desde que disponham sobre dinheiros, valores e bens públicos. Segundo, quaisquer pessoas que disponham sobre dinheiros, bens e valores, públicos ou privados, pelos quais a União responda total ou parcialmente. Terceiro, quaisquer pessoas que, em nome da União, assumam obrigações de natureza pecuniária, como a contratação de operações de crédito ou a concessão de garantias²

2 Vide parecer do Procurador-geral junto ao TCU, Dr. Lucas Rocha Furtado, exarado no TC010.937/2001-1 e transcrito no Acórdão 717/2004-Plenário. 
Note-se que o dever de prestar contas recai não apenas sobre pessoas que gerem recursos e valores públicos, mas também sobre aqueles que gerem recursos privados pelos quais a União responda integral ou parcialmente.

\section{A competência constitucional de julgar contas}

A competência julgadora dos Tribunais de Contas também tem estatura constitucional, assim como os próprios Tribunais de Contas, dada a relevância de uma e de outros nas Repúblicas, a ponto de o dever de prestar contas ter sido instado a princípio constitucional sensível, de modo que seu descumprimento pelos estadosmembros ser hipótese de intervenção federal.

Prevê o nosso texto constitucional que compete ao Tribunal de Contas da União "julgar as contas dos administradores e demais responsáveis por dinheiros e valores públicos da administração direta e indireta, incluídas as fundações e sociedades instituídas e mantidas pelo Poder Público Federal, e as contas daqueles que derem causa a perda, extravio ou outra irregularidade de que resulte prejuízo ao Erário" (art. 71, II), aplicando-se tal norma, no que couber, aos Tribunais de Contas dos Estados e do Distrito Federal (art. 75).

A interpretação conjunta dos dispositivos constitucionais que tratam do dever de prestar contas (art. $7^{\circ}$, parágrafo único) e da competência para julgar contas (art. 71, II) leva à conclusão de compete ao Tribunal de Contas da União: ${ }^{3}$

“a) julgar as contas dos administradores e demais responsáveis por dinheiros, bens e valores públicos da administração direta e indireta, incluídas as fundações e sociedades instituídas e mantidas pelo poder público federal; e

b) julgar as contas de qualquer pessoa física ou jurídica, pública ou privada, que der causa a perda, extravio ou outra irregularidade de que resulte prejuízo ao erário quando essa pessoa: (l) utilizar, arrecadar, guardar, gerenciar ou administrar dinheiros, bens e valores públicos; (2) utilizar, arrecadar, guardar, gerenciar ou administrar dinheiros, bens e valores pelos quais a União responda; ou (3) em nome da União, assumir obrigações de natureza pecuniária."

A competência do TCU estende-se aos demais Tribunais de Contas por força do art. 75 da Constituição Federal.

Note-se que nem todos aqueles "que derem causa a perda, extravio ou outra irregularidade de que resulte prejuízo ao Erário" têm contas julgadas, a exemplo de um motorista que, por acidente ou não, destrói ou derruba um poste de energia. Isso porque estão sujeitos ao julgamento de contas apenas aqueles a quem incumbe o dever de prestar contas, nos termos do art. $7^{\circ}$, parágrafo único, retrotranscrito. Assim, para que se possa julgar contas de quem deu causa a prejuízo ao erário é necessário que a pessoa se enquadre em uma das três hipóteses elencadas na letra " $b$ " supra. Não é o caso do motorista indicado no exemplo.

3 Vide parecer do Procurador-geral junto ao TCU, Dr. Lucas Rocha Furtado, já citado. 
Vamos agora submeter à análise o processo de julgamento de contas, de modo a perscrutar diversos aspectos da competência julgadora que se deseja compreender.

\section{As três dimensões do processo de contas}

Convém, preliminarmente, esquadrinhar a natureza jurídica do processo de contas, buscando luz ao nosso pensamento.

O processo de contas, nos Tribunais de Contas, contempla, a nosso ver, três dimensões relevantes, três vertentes necessárias ao cumprimento integral de seus fins. A primeira diz respeito ao julgamento da gestão do administrador responsável e é dita dimensão política; a segunda, à punibilidade do gestor faltoso e é dita dimensão sancionatória; e a terceira, à reparação do dano eventualmente causado ao erário e a chamo de dimensão indenizatória.

\section{A dimensão política: o julgamento da gestão}

A primeira dimensão - atinente ao julgamento da gestão do administrador responsável - parece-nos a mais importante entre as três, tendo em vista que realiza o princípio republicano de informar ao povo de como estão sendo utilizados - se bem ou mal - os recursos financeiros que, em sua maioria, lhe foram subtraídos compulsoriamente mediante tributação.

Essa dimensão é de natureza política, pois tende a limitar o poder do Estadoadministração na gestão dos bens e valores públicos, evitando ou procurando evitar os atos arbitrários. Tanto sua natureza é política que o julgamento pela irregularidade das contas, em decisão irrecorrível, pode vir a acarretar uma consequiência política, qual seja: a declaração, no âmbito da Justiça Eleitoral, de inelegibilidade do gestor faltoso, por período de cinco anos.

Os valores arrecadados pelo Estado, com base em seu poder de império, por axioma republicano, a ele não pertencem, mas sim à coletividade. O Estado, por meio de seus agentes, é mero administrador, e não dono (proprietário) desses recursos. E, não sendo dono, não tem o poder de dispor deles ao seu talante. Deve, ao contrário, usá-los de acordo com a vontade do verdadeiro dono - a coletividade e, além disso, prestar-lhe contas do bom uso.

Assim, ao Estado, além do dever de dispor dos recursos arrecadados de acordo com a vontade da coletividade, insculpida nas leis, isto é, de acordo com o interesse público, cumpre prestar-lhe contas desse uso.

Por conseguinte, o julgamento de contas, antes de ser interesse exclusivo do gestor responsável, concerne a toda a sociedade, pois que a ela está constitucionalmente assegurado o direito de conhecer como foram utilizados os recursos que lhe pertencem. E mais, são os Tribunais de Contas, no cumprimento de sua missão institucional, que concretizam esse direito da sociedade.

Desse raciocínio resulta que o principal destinatário do processo de contas é antes a coletividade do que o gestor. O gestor é destinatário secundário, tão apenas. 


\section{A dimensão sancionatória: a punibilidade do gestor faltoso}

A segunda dimensão do processo de contas, que é desdobramento da primeira, concerne à punibilidade do gestor faltoso, de maneira que tem natureza sancionatória.

Note-se que a dimensão política do processo é autônoma e determinante das outras. Para que ela se realize, basta que o processo tenha constituição e desenvolvimento válido.

A dimensão sancionatória, entretanto, é dependente e determinada pela política. É dependente porque, sem a apreciação dos atos de gestão, não poderá haver aplicação da pena ao administrador faltoso. É determinada porque a punição do administrador decorre do reconhecimento, no julgamento, da ocorrência de irregularidade na gestão.

À dimensão sancionatória aplica-se princípios regedores do direito penal, como o princípio da reserva legal, no sentido de que não há ilícito nem sanção sem lei anterior que os definam. Cabe também a retroação de lei mais favorável e a extinção da punibilidade com a morte do agente. Além disso, não deve a sanção ultrapassar a pessoa do condenado e não há responsabilidade objetiva, de modo que a aplicação da sanção é consequiência da ação, ou omissão, dolosa ou culposa do agente.

$\mathrm{Na}$ dimensão sancionatória, diferentemente da política, o processo dirige-se direta e imediatamente ao gestor. Somente o administrador deve sofrer as consequiências punitivas, em face da reconhecida má gestão. Isso, porque a aplicação da pena não pode ultrapassar a pessoa do condenado, conforme dispõe o art. $5^{\circ}$, inciso XLV, da Constituição Federal.

Por conseguinte, a morte do gestor - embora não seja, como veremos, óbice à continuidade do processo e ao julgamento das contas em razão da necessária concretização da dimensão política do processo - é causa de extinção da dimensão sancionatória, em virtude da extinção da punibilidade.

Em outras palavras, na hipótese de má gestão, o processo subsiste à morte do administrador, e as suas contas podem vir a ser julgadas, mas não se poderá aplicar sanção ao falecido ou, se tiver sido aplicada e ainda não cumprida, será ela extinta.

\section{A dimensão indenizatória: a reparação do dano causado ao erário}

A terceira dimensão diz respeito à reparação do prejuízo causado ao erário. Tem ela natureza indenizatória, sendo também dependente e determinada pela dimensão política. Exsurge ela do reconhecimento, no julgamento das contas, da ocorrência de dano ao erário.

À dimensão indenizatória aplicam-se as normas gerais regedoras da responsabilidade civil subjetiva. Assim para a condenação em débito, além da ocorrência do dano, faz-se necessário outros dois requisitos: o nexo de causalidade entre o dano e os atos (ou omissão) do gestor e ação (ou omissão) culposa ou dolosa. 
Nessa vertente e só nessa, o processo alcança os sucessores do administrador falecido. É que a esses, segundo o texto constitucional, estende-se a responsabilidade pela reparação do prejuízo causado, na medida do patrimônio transferido na sucessão (art. $5^{\circ}$, inciso XLV, da Constituição Federal, in fine).

Em verdade, antes da partilha da herança, não são os sucessores que respondem processualmente pelo dano, mas o espólio, na pessoa do inventariante ou do administrador provisório. No entanto, embora lembrando dessa ressalva. para facilitar a escrita, continuaremos a análise nos referindo apenas aos sucessores. Os sucessores não sofrem consequências jurídicas decorrentes da concretização das duas primeiras dimensões do processo de contas. Não respondem diretamente pela má gestão dos valores públicos, não podem, como veremos, titularizar as contas, não se tornam inelegíveis por contas julgadas irregulares nem podem ser constrangidos a cumprir as sançōes eventualmente aplicadas ao gestor em vida. A eles se estende, única e exclusivamente, a responsabilidade pela reparação do dano.

Retornemos agora às questões inicialmente colocadas.

\section{Deve o processo se extinguir com a morte do gestor?}

$\mathrm{Na}$ análise da primeira dimensão do processo, vimos que o principal destinatário do processo de contas é a coletividade. O gestor é apenas o destinatário secundário. Consequiência direta dessa afirmação é que a morte do gestor não é, por si só, obstáculo ao julgamento das contas nem causa de extinção do processo, pois. sempre que possível, deve subsistir a finalidade precípua do processo, de natureza política, que é a de dar ciência à coletividade acerca da utilização, boa ou má, dos recursos que the pertencem. Assim, salvo situações excepcionais, faz-se necessário que, mesmo após o falecimento do gestor, sejam as contas julgadas para que se dê satisfação à coletividade de como foram aplicados os seus recursos.

Outrossim, ao analisarmos a dimensão indenizatória do processo, vimos que, por força de edito constitucional, a responsabilidade patrimonial de reparar eventual dano causado ao erário transfere-se do gestor falecido aos sucessores, na medida do patrimônio recebido. Dessa maneira, é de mister que, mesmo após a morte do gestor, o processo prossiga seu curso a fim de que também essa dimensão se concretize.

Com efeito, a dimensão sancionatória do processo é a única que se extingue com a morte do gestor, uma vez que o cumprimento da sanção é personalíssimo, pois não ultrapassará a pessoa do condenado. As outras duas dimensões, contudo, podem e devem ser realizadas.

Convém lembrar que podem ocorrer situações em que o julgamento das contas fica prejudicado em face do falecimento do titular. Por exemplo, no caso de serem verificadas, pelo Tribunal, supostas irregularidades sem ocorrência de débito, morrendo o gestor antes da realização da audiência prévia. Nesse caso, a falta da audiência prévia, que é instrumento processual concretizador dos princípios constitucionais da ampla defesa, do contraditório e do devido processo legal, impede o desenvolvimento válido e regular do processo, causando a sua extinção. 


\section{Quem é o titular das contas?}

Quem recebe a incumbência de gerir bens ou valores públicos está adstrito ao dever constitucional e legal de prestar contas. Há, portanto, na relação jurídica que se estabelece, dois deveres: o de bem gerir a coisa pública e o de prestar contas da gestão.

Em nossa opinião, é titular das contas quem se incumbe desses dois deveres. Assim, titular das contas é quem assume os deveres de bem gerir e de prestar as contas da gestão dos bens ou valores públicos recebidos. É titular das contas, portanto, quem efetivamente administra os bens ou valores públicos colocados à sua disposição e assume a responsabilidade de deles prestar contas.

O titular das contas é o agente cuja gestão se aprecia. Com a nova redação do parágrafo único do artigo $7^{\circ}$ da Constituição Federal, dada pela Emenda $n^{\circ} 19$, de 1998, além das pessoas físicas, podem vir a prestar contas também as pessoas jurídicas, públicas ou privadas, de maneira que, atualmente, todas essas espécies de pessoas podem vir a titularizar contas.

Em algumas situações excepcionais, pode ocorrer a cisão dos mencionados deveres. Por exemplo, quando a gestão dos recursos ocorre em período de tempo que abrange o mandato de mais de um gestor, sendo que o último, além da prestação das contas, poderá ainda estar incumbido de parte da gestão. Nesses casos, entendemos que todos são titulares das contas, no entanto respondem na medida dos deveres que receberam.

Resta agora saber se a morte do gestor implica a transferência da titularidade das contas a outrem.

A nosso ver, a resposta deve ser não.

Julgar contas, em sentido material, é julgar gestão. É apreciar, por meio dos documentos apresentados ou de outra forma obtidos, os atos de gestão praticados pelo responsável sobre aqueles bens ou valores públicos, segundo os critérios da legalidade, legitimidade e economicidade.

Dessa maneira, não vemos obstáculos a que o gestor, mesmo após a morte, continue a ser o titular das contas, simplesmente porque o que se pretende apreciar ou julgar são antes os atos de gestão que ele praticou em vida do que a sua própria pessoa, extinta com a sua morte.

Segundo o entendimento que expressamos, os sucessores não podem ser titulares de contas, em substituição ao gestor falecido, porque aos sucessores não se transferem os deveres de bem gerir a coisa pública e de prestar contas. Por conseguinte, não se transfere a eles a responsabilidade pelos atos de má gestão nem a eles se estende a perda do direito de serem elegíveis, em razão de contas julgadas irregulares, por decisão irrecorrível. Não sofrem eles, também, as consequiências jurídicas de natureza sancionatória, pois essas dirigem-se unicamente ao gestor faltoso.

Aos sucessores se estende, única e exclusivamente, a responsabilidade pela reparação do dano eventualmente causado ao erário, na medida do patrimônio recebido, conforme se verifica no art. $5^{\circ}, \mathrm{XLV}$, da Constituição Federal. Os sucessores são alcançados, por extensão, tão-somente pela responsabilidade patrimonial 
de reparar o dano, desde que comprovada a efetiva lesão ao erário e o nexo de causalidade entre essa e a conduta, culposa ou dolosa, do gestor.

$O$ texto constitucional fala por si mesmo:

"XLV - nenhuma pena passará da pessoa do condenado, podendo a obrigação de reparar o dano e a decretação do perdimento de bens ser, nos termos da lei, estendidas aos sucessores e contra eles executadas, até o limite do valor do patrimônio transferido" (grifou-se).

Assim, os sucessores ou o espólio, em nossa opinião, vêm integrar o pólo passivo do processo, não como titulares das contas, mas como sujeitos processuais de outra natureza, respondendo pelos danos eventualmente causados pelo gestor falecido, no desdobramento da dimensão indenizatória do processo de contas.

\section{A quem se deve dirigir a citação ou a audiência prévia?}

A audiência prévia é ato processual que visa chamar o responsável ao processo para apresentar defesa, em razão de irregularidades verificadas, das quais não resulta a ocorrência de dano. Realiza, portanto, os princípios da ampla defesa, do contraditório e do devido processo legal, com vistas à aplicação, se for o caso, de sanção ao gestor faltoso.

Tendo em vista que a pena não pode ultrapassar a pessoa do gestor faltoso, somente a ele pode ser dirigida a audiência prévia e, se esse gestor vier a falecer antes de ser promovida a oitiva, não poderá ela ser estendida aos sucessores.

A citação é também ato processual que, realizando os mencionados princípios constitucionais, visa chamar o responsável ao processo, distinguindo-se da audiência prévia porque (a) é restrita ao processo de contas; (b) é própria para irregularidades de que resulta a ocorrência de dano e (c) chama o responsável ao processo para recolher o débito apurado, como alternativa à apresentação de defesa. A citação deve ser dirigida, em regra, ao gestor que praticou a irregularidade e, solidariamente, àqueles que, de algum modo, contribuíram para a ocorrência do dano.

Se o gestor faltoso vier a falecer e tendo em vista que o erário pode satisfazer-se no patrimônio transferido ou a ser transferido aos sucessores, a definição do destinatário da citação dependerá do momento em que estiver sendo ela expedida.

Quatro situações distintas podem acontecer.

Primeira: o momento de expedição da citação é anterior à nomeação do inventariante. Nesse caso, a citação deve ter como destinatário o espólio, representado pela pessoa do administrador provisório da herança (arts. 985 e 986 do Código de Processo Civil), que é "aquele que dá continuidade prática à posse do autor da herança, enquanto não ocorre a investidura do inventariante" (THEODORO JÚNIOR, Humberto. Curso de Direito Processual Civil. $9^{\mathrm{a}}$ ed., Rio, Forense, 1994, vol. III, p. 265).

O administrador provisório será o cônjuge sobrevivente nos casos de casamento sob regime de comunhão de bens. Se não houver cônjuge supérstite ou se o regime 
matrimonial não for o de comunhão de bens, o administrador será o herdeiro que se encontre na posse do acervo a inventariar (THEODORO JÚNIOR, Humberto. Ob. cif., p. 266).

Segunda: o momento de expedição da citação é posterior à nomeação do inventariante mas anterior à partilha. Nesse caso, a citação deve ser dirigida ao espólio, representado pela pessoa do inventariante (arts. 985 e 990 do Código de Processo Civil), que é a "pessoa nomeada pelo juiz para administrar o acervo hereditário e promover o inventário e a partilha" (THEODORO JÚNIOR, Humberto. Ob. cit., p. 266), segundo a ordem legal prevista no artigo 990 do Código de Processo Civil.

Terceira: o momento de expedição da citação é posterior à partilha. Nesse caso, a citação deve ser dirigida diretamente aos sucessores.

Quarta: quando não há sucessores conhecidos e a herança é jacente. Nesse caso, a citação deve ser dirigida ao curador da herança, pois ele a representa em juízo, conforme o art. 1.144, inciso I, do Código de Processo Civil. Na hipótese de não se ter realizado o procedimento de arrecadação da herança jacente nem ter sido nomeado o curador da herança, o Tribunal, mediante diligência, poderá provocar o juiz estadual da comarca em que era domiciliado o falecido, a fim de que ele, no exercício de sua competência privativa (art. 1.142 do Código de Processo Civil), promova a instauração do aludido procedimento e a nomeação do referido curador.

Ao se ter notícia do falecimento do gestor, muitas vezes não se sabe se o morto deixou patrimônio, se há ou não sucessores, se existe o processo de inventário nem se já foi realizada a partilha. Dessa maneira, a fim de que se possa bem decidir sobre a realização da citação ou para quem ela será dirigida, convém, até como medida de economia processual, a promoção, em preliminar, de diligência junto ao juízo competente da comarca do último domicílio do gestor falecido, com vistas a obter essas informações.

É oportuno ainda anotar que, na vigência do Código Civil de 1916, o cônjuge sobrevivente não era, em regra, considerado sucessor, mas meeiro. Com o Novo Código Civil, essa situação mudou, vez que, na ordem da vocação hereditária da sucessão legítima, o cônjuge passou a concorrer com os descendentes e também com os ascendentes. Na concorrência, cabe ao cônjuge quinhão igual ao dos que sucederem por cabeça, garantido, na concorrência com ascendentes, o quinhão mínimo correspondente à quarta parte da herança (arts. 1.829, I e II, e 1.832).

\section{Que é quitação?}

Resta enfrentar as questões pertinentes à natureza e ao beneficiário da quitação.

Cumpre agora perscrutar a natureza jurídica da quitação, no âmbito do processo administrativo da Corte Federal de Contas, que nos parece peculiar. A nosso ver, a aludida quitação é um ato administrativo unilateral, vinculado, de competência privativa dos Tribunais de Contas, em que esses declaram desonerado o responsável perante a coletividade, em face do adimplemento do dever de comprovar a boa gestão dos bens ou valores públicos colocados à sua disposição (dimensão política), ou, na hipótese de má gestão, de ressarcir o prejuízo causado ao erário (dimensão indeni- 
zatória) e/ou de cumprir a sanção que lhe tenha sido aplicada (dimensão sancionatória).

Note-se que a quitação pode, na hipótese de má gestão dos recursos, alcançar as três dimensões do processo de contas.

A quitação é, portanto, ato administrativo unilateral de natureza declaratória, expedido em face do adimplemento do dever, seja de comprovar a boa gestão dos bens ou valores públicos, seja de ressarcir o prejuízo causado e/ou de cumprir a sanção aplicada. A quitação é a declaração de que resta adimplido um dever. $O$ dever, na hipótese de boa gestão, abrange tão-somente a apresentação das contas comprovando essa boa gestão, enquanto, na hipótese contrária, alberga ainda a reparação do dano e/ou o cumprimento da sanção aplicada.

Convém salientar que a expedição da quitação não implica necessariamente a boa gestão dos bens ou valores públicos.

\section{A quem se deve dar quitação?}

É de salientar, primeiramente, que a expressão "dar quitação", de uso corrente no Tribunal de Contas da União, não é, a meu ver, apropriada à natureza jurídica meramente declaratória da quitação. A inadequação consiste em que a utilização do verbo "dar" pressupõe a existência do sujeito que a "recebe", embora o aperfeiçoamento da quitação não dependa da manifestação da vontade ou da existência do destinatário, simplesmente porque é ato unilateral de natureza declaratória.

Mais consentâneo com essa-natureza seria o uso da expressão "declarar a quitação", em vez de "dar a quitação". No entanto, não se pode olvidar que o uso da segunda expressão, além de estar em consonância com a lei, está consagrado na jurisprudência da Corte de Contas, de maneira que seria difícil modificá-la e, por isso, continuamos a utilizá-la.

Retomando à questão: a quem se deve dar quitação? ou melhor, de quem se deve declarar a quitação? A nosso ver, cabe quitação, em regra, ao titular das contas, depois de adimplido o dever de comprovar a boa gestão ou de ressarcir o dano e/ou de cumprir a sanção aplicada — esse é o critério básico que identifica o destinatário da quitação.

Em algumas situações, poderá caber também quitação aos co-responsáveis não-gestores (por exemplo, o terceiro contratado que, de alguma forma, contribuiu para o cometimento do dano) e aos sucessores do falecido. Note-se que é devida a quitação aos sucessores no âmbito da dimensão indenizatória, tão apenas pela efetiva reparação do dano, e aos co-responsáveis não-gestores pela reparação do dano e/ou cumprimento da sanção aplicada.

Não vemos impedimento a que se dê quitação a gestor falecido, mesmo se se considerar o argumento de que já não existe a pessoa destinatária da quitação. Primeiro, porque ele, mesmo morto, permanece como titular das contas e a quitação, como vimos, cabe precipuamente a esse titular. Segundo, porque a quitação é ato administrativo unilateral de natureza declaratória, de maneira que o seu aperfeiçoa- 
mento independe da manifestação da vontade do destinatário ou da existência dele no momento em que for expedida.

\section{Como proceder no exame de casos concretos relativos a gestor falecido?}

Neste ponto, deixamos o terreno aprazível e fértil da teoria e das idéias para adentrar, por necessário, as terras áridas e pedregüentas dos casos concretos. Três hipóteses distintas se apresentam para exame. A primeira, quando se verifica a boa gestão dos bens ou valores públicos. A segunda, quando se verifica a má gestão, sem a ocorrência de dano ao erário. A terceira, quando há a má gestão e dela decorre prejuízo ao erário.

\subsection{A hipótese de boa gestão}

Na hipótese de boa gestão dos bens ou valores públicos, não se realizam as dimensões sancionatória e indenizatória do processo, mas tão-somente a dimensão política. O processo cumpre os fins de informar a coletividade da boa gestão da coisa pública e de declarar a quitação do gestor.

Aplicando-se os critérios previamente estabelecidos, o gestor, mesmo morto, será o titular das contas e, por conseguinte, o beneficiário da quitação. Será o titular das contas porque lhe foram confiados os deveres de bem gerir os recursos públicos e de prestar as contas. Tendo ele cumprido, em vida, esses deveres, terá contas julgadas regulares e ser-lhe-á devida a quitação.

Os Tribunais de Contas, então, deverão julgar as suas contas regulares, ou regulares com ressalvas, expedindo-lhe a quitação.

\subsection{A hipótese de má gestão sem a ocorrência de dano}

Nessa hipótese, podem ocorrer duas situações.

A primeira: as contas não são julgadas e o processo é arquivado, em razão de o falecimento do gestor ter ocorrido antes da realização da audiência prévia. Nesse caso, por impossibilidade de realização do necessário contraditório, o processo não deve prosseguir, a gestão não é apreciada, e, por isso, não há falar em quitação. Como o processo não chega ao fim, nenhuma dimensão dele é concretizada. A não-realização do contraditório decorre da morte do gestor e da impossibilidade de trazer os sucessores ao processo, em virtude da ausência de dano.

A segunda: o falecimento do gestor ocorre após a realização da audiência prévia, e as contas são julgadas com aplicação, ou não, de sanção. Nessa hipótese, ha de se considerar duas situações:

Primeira, se a morte é posterior ao julgamento, ou se o Tribunal toma ciência da morte somente após o julgamento, e se tiver havido a aplicação de sanção, com a morte há a extinção da punibilidade, e, consequientemente, do dever de cumprir a sanção. Nesse caso, entendemos que é devida a quitação ao gestor falecido a ser 
expedida em nova decisão da Corte de Contas em atendimento à dimensão política, porque ele é o titular das contas e não lhe resta nenhum dever a cumprir.

Segunda, se a morte é posterior à promoção da audiência prévia mas anterior ao julgamento, o Tribunal, tendo ciência do falecimento antes do julgamento, não deve aplicar a sanção, em virtude da extinção da punibilidade. Não sendo aplicada a sanção, não há o dever de cumpri-la, de maneira que, no julgamento, se deve expedir, desde logo, em atendimento à dimensão política, a quitação ao gestor falecido, pelos mesmos motivos já mencionados.

O julgamento das contas, nessas circunstâncias, concretiza apenas a dimensão política do processo, já mencionada, restando prejudicada a dimensão sancionatória, em face da extinção da punibilidade.

\subsection{A hipótese de má gestão com a ocorrência de dano}

De pronto, esclareça-se que, nessa hipótese. a defesa e o contraditório, em tese, não ficam prejudicados com a morte do gestor e o processo pode prosseguir sem obstáculos, uma vez que os sucessores podem ser chamados a integrar o pólo passivo da relação processual, tendo em vista que a eles se estende a responsabilidade de reparar o dano, na medida do patrimônio recebido. Ressalve-se que, em situações específicas, pode ficar demonstrada a impossibilidade fática de os sucessores se defenderem, inviabilizando o contraditório. Os Tribunais de Contas, nesses casos excepcionais, poderão arquivar o processo, sem julgamento, por falta de pressuposto de desenvolvimento válido.

Duas situações podem acontecer, dependendo da existência ou não de patrimônio do de cujus. Note-se que, mesmo que não haja sucessores, havendo patrimônio, esse comporá a herança jacente e, por fim, passará ao domínio do Município, do Distrito Federal ou da União, conforme os arts. 1.822 do Novo Código Civil.

Comprovada a inexistência de patrimônio a ser transferido pela sucessão, não ocorrerá a extensão da responsabilidade de reparar o dano aos sucessores, uma vez que a mencionada transferência patrimonial é condição necessária à efetivação da responsabilidade dos sucessores, conforme o art. $5^{\circ}, \mathrm{XLV}$, da Constituição Federal, e $5^{\circ}$, VIII, da Lei ${ }^{\circ} 8.443 / 92$.

A inexistência de patrimônio do de cujus, cumpre assinalar, não extingue o débito e, por conseguinte, não extingue o dever de reparação ao erário, apenas impede a extensão desse dever aos sucessores. Assim, se as contas vierem a ser apreciadas (quando o falecimento do gestor ocorrer após citação válida), entendemos que se deva julgar irregulares suas contas e condenar em débito o gestor falecido, não lhe sendo devida a quitação, uma vez que não se extinguiu o débito nem o dever de reparar o dano.

Permanecendo tal dever, não há que se declarar o seu adimplemento, não há falar em quitação. Se, posteriormente, vierem a ser encontrados bens pertencentes ao falecido, não haverá empecilho a que se possa, em processo de execução, buscar-se o ressarcimento ao erário. Tal situação poderá, oportunamente, resultar em expedição de quitação a quem recolher o débito e ao gestor falecido. 
É bom de ver que o débito não se constitui com o julgamento das contas, quando o gestor já está morto, mas muito antes, quando esse, em vida, praticou os atos irregulares que resultaram em prejuízo ao erário. $O$ julgamento em débito tem também natureza declaratória, tornando a dívida líquida e certa.

Tanto isso é verdade que, por meio da citação, o responsável é chamado ao processo para apresentar defesa ou recolher o débito. Evidentemente, já no momento da citação, que de muito antecede o julgamento, o débito está devidamente constituído, caso contrário, não se poderia chamar o responsável para recolhê-lo.

Por outro lado, existindo o patrimônio e tendo havido, com a morte, a sua transferência aos sucessores, após a citação deles, as contas devem ser julgadas e, se o débito vier a ser recolhido pelos sucessores, deve-se dar quitação a eles, porque cumpriram o dever de reparar o dano causado ao erário (dimensão indenizatória) e ao gestor falecido, porque ele geriu os recursos e é o titular das contas (dimensão política). Assim, concretizam-se a primeira e a terceira dimensão do processo. Nesse caso, poder-se-ão julgar irregulares as contas do gestor falecido e em débito os sucessores, por força do art. $5^{\circ}$, XLV, da Constituição Federal. A eventual cumulação de sanção e débito em nada muda esse raciocínio, em virtude da extinção da punibilidade do falecido.

Note-se ainda que não há solidariedade entre os sucessores, pois cada um responde na medida do patrimônio que efetivamente recebeu.

É de salientar que quando os sucessores, por meio de defesa, descaracterizam o dano, afastam, ipso facto, a responsabilidade que lhes é imputada.

Além de ilidir a responsabilidade, a descaracterização do dano implica a exclusão deles do processo, vez que, sem a existência de débito, a dimensão indenizatória do processo de contas não se concretiza, tornando-se dispensável a existência dos sujeitos que a suportem.

Se resta eliminada a responsabilidade dos sucessores, não thes é exigível o cumprimento do dever de indenizar o erário; logo, não lhes cabe receber quitação, pois a quitação é expedida em face do adimplemento de um dever.

\section{Conclusão}

Convém, por fim, salientar que as idéias-força que nortearam o desenvolvimento deste trabalho acerca da competência julgadora dos Tribunais de Contas - tais como a tridimensionalidade do processo de contas, a determinação dos destinatários principal e secundário de tal processo, a identificação do titular das contas e do beneficiário da quitação, assim como a natureza jurídica da quitação - integram, vamos assim dizer, uma teoria geral que está ainda por ser construída e, por isso, são aplicáveis às multifárias situações-problema enfrentadas no labor cotidiano exercido nos Tribunais de Contas, de maneira que esperamos que tais idéias sejam úteis a todos aqueles que têm por missão resolvê-las. 


\section{A Estrutura Lógica do Direito}

Arthur José Faveret Cavalcanti

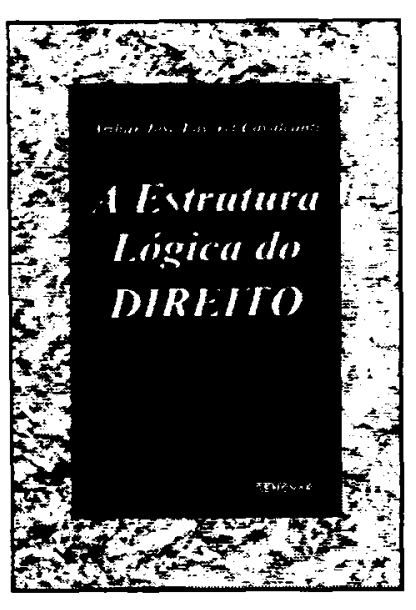

Este livro é uma teoria geral do direito. Há velhos temas abordados de forma inusitada. O tratamento dado à questão da personalidade jurídica é um exemplo. Sāo também vistas questōes que até aqui haviam passado despercebidas, como a de elucidar as relaçōes lógicas entre normas pertencentes ao mesmo ordenamento. Para lançar luz sobre pontos obscuros, os leitores são convidados a participar de experimentos mentais.

\author{
Ref. 0124
}

Form. 14x21

347 págs.
Brochura 1996

\section{A Evolução da Ordem Pública no Direito Internacional Privado}

Jacob Dolinger

Esta obra versa o princípio da ordem pública no direito internacional privado, que representa a mais importante "válvula de escape" de que se utilizam juizes e tribunais do mundo todo, para deixar de aplicar a lei estrangeira indicada pelas regras de conexão, sempre que sentirem que a norma estrangeira não é consentânea com os princípios fundamentais do direito do foro.

$\begin{array}{lll}\text { Ref. 0071 } & \text { Distribuição } & \text { Brochura } \\ 282 \text { págs. } & \text { Form. } 16 \times 23 & 1979\end{array}$

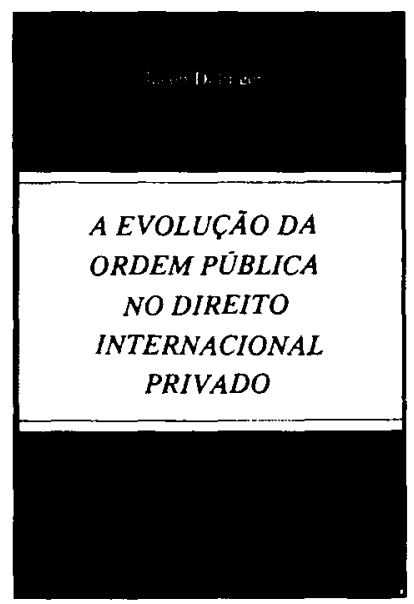

